Jean-Claude Lefebvre

Aissam Lyazidi

Miguel Parceiro

Giuseppe F. Sferrazza Papa

Evangelia Akoumianaki

Deborah Pugin

Didier Tassaux

Laurent Brochard

Jean-Christophe M. Richard

\section{Bench testing of a new hyperbaric chamber ventilator at different atmospheric pressures}

Received: 29 December 2011

Accepted: 18 April 2012

Published online: 17 May 2012

(C) Copyright jointly held by Springer and ESICM 2012

Electronic supplementary material The online version of this article (doi:10.1007/s00134-012-2590-4) contains supplementary material, which is available to authorized users.

J.-C. Lefebvre (®) · A. Lyazidi • G. F. Sferrazza Papa - E. Akoumianaki . D. Pugin - D. Tassaux · L. Brochard . J.-C. M. Richard

Intensive Care Department, Geneva University Hospital, 4 Rue Gabrielle PerretGentil, 1211 Genève 14, Switzerland

e-mail: jclefebvre31@ @otmail.com; jcm.richard@hcuge.ch

Tel.: +33-62-2115851

\section{J.-C. Lefebvre}

Intensive Care Unit, Centre hospitalier universitaire de Québec, Québec, Canada

A. Lyazidi - D. Tassaux - L. Brochard . J.-C. M. Richard

Medical School, University of Geneva, Geneva, Switzerland

M. Parceiro

Hyperbaric Medicine Unit, Geneva

University Hospital, Geneva, Switzerland
G. F. Sferrazza Papa

Clinica di Malattie dell'Apparato Respiratorio, Ospedale San Paolo, Università degli Studi di Milano, Milan, Italy

Abstract Purpose: Providing
mechanical ventilation is challenging
at supra-atmospheric pressure. The
higher gas density increases resis-
tance, reducing the flow delivered by
the ventilator. A new hyperbaric
ventilator (Siaretron IPER 1000) is said to compensate for these effects automatically. The aim of this bench test study was to validate the compensation, define its limits and provide details on the ventilator's output at varied atmospheric pressures. Methods: Experiments were conducted inside a multiplace hyperbaric chamber at 1, 2.2, 2.8 and 4 atmospheres absolute (ATA), with the ventilator connected to a test lung.

Transducers were recalibrated at each ATA level. Various ventilator settings were tested in volume and pressure control modes. Measured tidal volumes were compared with theoretical predictions based on gas laws.

Results: Results confirmed the ventilator's ability to provide compensation, but also identified its limits. The compensation range could be predicted and depended on the maximal flow attainable, decreasing linearly with increasing atmospheric pressure. With settings inside the range, tidal volumes approximated set values (mean error $10 \pm 5 \%$ ). With settings outside the range, the volume was limited to the predicted maximal value calculated from maximal flow. A practical guide for clinicians is provided. Conclusion: The IPER 1000 ventilator attempted to deliver stable tidal volume by adjusting the opening of the inspiratory valve in proportion to atmospheric pressure. Adequate compensation was observed, albeit only within a predictable range, which can be reliably predicted for each setting and ATA level combination. Setting a tidal volume outside this range can result in an unwanted decrease in minute ventilation.

Keywords Hyperbaric oxygen therapy - Mechanical ventilation . Ventilator · Volume-control . IPER $1000 \cdot$ Gas density

\section{Introduction}

Hyperbaric oxygen therapy (HBOT) is used in the treatment of several acute medical conditions, including decompression sickness, carbon monoxide poisoning and necrotizing infections [1]. In recent years, technical advances and a better understanding of mechanical ventilation under hyperbaric pressure have contributed to the 
increasing use of HBOT in the treatment of critically ill patients. Nevertheless, applying HBOT to mechanically ventilated patients remains challenging because of safety and technical reasons [2]. Devices used in the hyperbaric chamber must resist the crushing effect of pressurization, while electronic components must operate at low voltage to mitigate the risk of fire hazard in the oxygen-enriched environment, precluding the use of conventional ventilators $[1,3]$. The higher gas density at supra-atmospheric pressure increases resistance, reducing the flow delivered by the ventilator $[4,5]$. This is frequently worsened by the suboptimal performance of hyperbaric-approved ventilators $[2,5,6]$.

A hyperbaric ventilator combining safety and acceptable performance, mostly in terms of sufficient and stable minute ventilation $\left(\mathrm{V}_{\mathrm{E}}\right)$, is clearly needed. Ideally, it should be portable, user friendly, with adequate alarms and various ventilation modes, notably assisted ones (as opposed to fully controlled ventilation). To our knowledge, the recently released Siaretron IPER 1000 (Siare, Bologna, Italy; distributed by Haux Life-Support, Karlsbad-Ittersbach, Germany) is the only ventilator approved for use inside the chamber that offers assisted modes of ventilation and automatic adjustment of the inspiratory valve opening to provide stable flow regardless of the ambient pressure.

The IPER 1000 has never been bench tested independently under hyperbaric pressure. This study was carried out to evaluate the performance and operational characteristics of the IPER 1000. Since this ventilator is said to compensate for the effects of increased gas density automatically, we compared the measurements obtained in supra-atmospheric conditions with theoretical calculations based on gas laws. This allowed us to (1) estimate the amount of compensation provided by the ventilator; (2) test and understand its limits; and (3) provide users with practical information about its operational range.

\section{Materials and methods}

The IPER 1000 is a portable electropneumatic ventilator, functioning with a low-tension electrical circuit and compressed medical gases. Volume-assist control (VC) and pressure-assist control (PC) modes are available, in addition to pressure support (PS). There is no integrated volume/flow monitoring (nor alarms), but the airway pressure (Paw) is displayed on a bar graph, and there is a low/high Paw alarm. The device is CE certified in accordance with European regulations, but is not yet available in the US, pending FDA approval.

All the experiments were conducted inside a multiplace hyperbaric chamber (Haux-Starmed 2400, Haux Life-Support, Germany) at 1, 2.2, 2.8 and 4 atmospheres absolute (1 ATA = atmospheric pressure). The IPER 1000 was connected to a passive Michigan test lung (Michigan Instruments, Grand Rapids, MI, USA) using an 8-mm endotracheal tube and a double-limb circuit [7, 8]. Compliance was set at $50 \mathrm{ml} \mathrm{cmH} \mathrm{CO}^{-1}$, without additional resistance. The ventilator, test lung and sensors were placed inside the chamber, while the data collecting units were kept outside for safety reasons. Four set tidal volume $\left(V_{\mathrm{T}} ; 250,500,750\right.$ and $\left.1,000 \mathrm{ml}\right)$ and inspiratory pressures (Pinsp; 5, 10, 15, $20 \mathrm{cmH}_{2} \mathrm{O}$ ) were tested in $\mathrm{VC}$ and PC, respectively, with the following settings: respiratory rate (RR) 15 cycles $\mathrm{min}^{-1}$, no inspiratory pause, positive end-expiratory pressure (PEEP) $5 \mathrm{cmH}_{2} \mathrm{O}$ and $\mathrm{FiO}_{2} 21 \%$. The inspiratory time was modified by varying the inspiratory:expiratory ratio (I:E): 1:2, 1:3, 1:4. Detailed methods are presented in the online supplement.

\section{Theoretical predictions}

Due to compression, gas density increases linearly with ambient pressure, with density being doubled at 2 ATA $[2,9]$. This higher density increases resistance to gas flow. Since ventilators control flow through the proportional opening of the inspiratory valve, greater resistance results in decreased flow across the valve for a given aperture $[4$, 10].

The difference in gas density determines the impact on flow and hence on delivered $V_{\mathrm{T}}$. We calculated the theoretical $V_{\mathrm{T}}$ predicted by the effects of gas laws only, using a volume correction factor detailed in the online supplement:

$$
\text { Volume correction factor }=\sqrt{\frac{\operatorname{gas} \rho(1 \mathrm{ATA})}{\operatorname{gas} \rho(x \mathrm{ATA})}}=\sqrt{\frac{1}{x}}
$$

where gas $\rho=$ gas density; $x=$ current ATA level. Since they are linearly correlated, the ATA level can directly replace gas density in the equation.

The IPER 1000 compensates for hyperbaric pressure by adjusting the opening of the inspiratory valve in proportion to the ambient pressure. This should function until the maximal valve opening area is attained; the flow then generated dictates the upper limit of the compensation range. According to the manufacturer, the maximal flow $\left(\right.$ flow $_{\max }$ ) at 1 ATA is $991 \mathrm{~min}^{-1}$, and we hypothesized a direct linear decrease with increasing ATA level (e.g., $251 \mathrm{~min}^{-1}$ at 4 ATA). We subsequently determined the predicted maximal $V_{\mathrm{T}}$ attainable $\left(V_{\mathrm{Tmax}}\right)$ for each experimental condition by multiplying the flow $_{\max }$ by the set inspiratory time. The $V_{T \max }$ fixed the upper limit of the compensation range. In theory, the decline in $V_{\mathrm{T}}$ should be less of an issue with PC, since the ventilator should intrinsically compensate for the decrease in flow to attain the target Pinsp [4]. 


\section{Results}

As predicted, peak flow was progressively limited with higher ambient pressures, decreasing linearly by a factor proportional to the ATA level, confirming our hypothesis of a predictable flow $_{\max }$ (Fig. 1). The area under the flow $_{\max }$ values delineates the range of compensation, the ventilator being unable to generate higher flow for a given ATA level. The complete results obtained in VC are displayed in Table 1. The mean error of the delivered $V_{\mathrm{T}}$ was only $5 \pm 4 \%$ at 1 ATA. Performances were progressively less accurate with increasing ambient pressure, but the results can be dichotomized according to theoretical predictions of the compensation range. At supraatmospheric pressures, for settings inside the range (i.e., under $V_{\text {Tmax }}$ ), the $V_{\mathrm{T}}$ did not decrease as predicted based on gas laws, but remained roughly stable (mean error of $10 \pm 5 \%$ ), confirming adequate compensation. Conversely, with settings outside the range (bold-italic values in Table 1), the delivered $V_{\mathrm{T}}$ differed widely from the set values, but were in close agreement with our predicted $V_{\text {Tmax }}(3 \pm 3 \%)$, indicating the inability of the ventilator to exceed $V_{\text {Tmax }}$. As the experimental results confirmed our theoretical predictions, we produced a practical user's guide, fixing the range of compensation of the IPER 1000 at frequently used settings (Table 2).

A progressive loss of PEEP of $2-3 \mathrm{cmH}_{2} \mathrm{O}$ was revealed (40-60\% of the set value) for all experimental settings, without being significantly influenced by the ATA level. Importantly, an aberrant insufflation, with

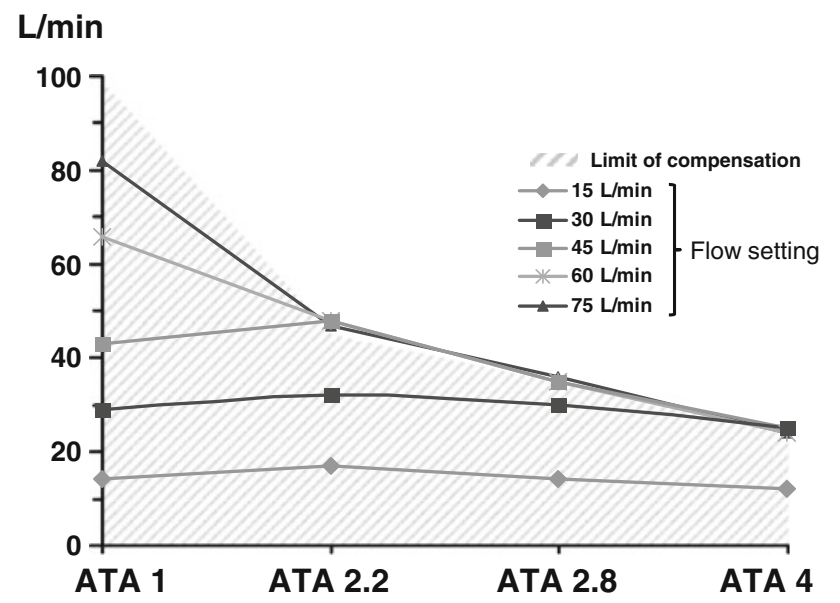

Fig. 1 Changes in peak flow with increasing atmospheric pressure. The figure shows the change in measured peak flow at various flow settings and ambient pressures. The IPER 1000 maintains a stable flow despite increasing atmospheric pressure, but only up to the point where the predicted flow $_{\max }$ is reached. This flow $\max$ decreased with increasing ATA level. From the flow max $_{\text {values at }}$ each ATA level $\left(991 \mathrm{~min}^{-1}\right.$ at 1 ATA, $451 \mathrm{~min}^{-1}$ at 2.2 ATA, $351 \mathrm{~min}^{-1}$ at 2.8 ATA and $251 \mathrm{~min}^{-1}$ at 4 ATA), a schematic zone of compensation can be represented (hatched area). ATA absolute atmosphere, flow $_{\max }$ predicted maximal attainable flow high delivered $V_{\mathrm{T}}$, was frequently noticed immediately after setting modifications during ventilation (e-figure 5). The results obtained in PC are detailed in the online supplement (e-table 1). In short, large discrepancies were frequently found between the measured and the predicted $V_{\mathrm{T}}$. This can be mainly attributed to the flow limitation at higher ATA levels, preventing the ventilator from attaining the target Pinsp (e-table 1 and e-figure 1).

\section{Discussion}

Our results confirmed that the IPER 1000 compensated for the greater resistance induced by higher gas density, apparently by increasing the opening of the inspiratory valve in proportion to the ATA level. However, this compensation only takes place inside an operational range, which becomes narrower at higher ATA levels. This range was shown to be reliably predicted using the theoretical flow $_{\max }$ for each ATA level. Users must be aware of this range to prevent an unnoticed decrease in $V_{\mathrm{E}}$, as there is no built-in volume monitoring. The practical guide presented in Table 2 might give a good estimate of the $V_{\text {Tmax }}$ for a given condition. Clinicians should not expect delivered $V_{\mathrm{T}}$ to be higher than $V_{\mathrm{Tmax}}$. The highest attainable $V_{\mathrm{E}}$ is quite low at the higher ATA levels $\left(6.21 \mathrm{~min}^{-1}\right.$ at 4 ATA; $4.21 \mathrm{~min}^{-1}$ at 6 ATA, with a 1:3 ratio), which could be insufficient for patients with moderate-high ventilatory needs.

In clinical practice, it is recommended that the IPER 1000 be used with an independent volumeter. Since results are more predictable in VC, this mode should be used preferentially, especially as predictions in PC would be even harder because of the patient's variable respiratory mechanics. Ventilator settings should correspond to the predicted values in Table 2 . If the clinical adequacy of the maximal $V_{\mathrm{E}}$ is doubtful, one should consider evaluating its impact on the patient before attempting HBOT with the IPER 1000. Using a 1:2 instead of 1:3 I:E ratio increases the maximal $V_{\mathrm{E}}$, but this should be done carefully because of the risk of dynamic hyperinflation, further magnified by the relatively high resistance of the exhalation apparatus (online appendix). To limit the impact of ventilating the fixed dead space, the use of a respiratory frequency in the low range $(\approx 10 / \mathrm{min})$ along with a relatively high $V_{\mathrm{T}}$ (limited by the $V_{\mathrm{T} \max }$ ) should be considered, at least for higher ATA levels.

With respect to study limitations, only one ventilator unit was tested, but the concordance between predicted and measured values suggests reproducible results. Even if a systematic decrease in PEEP is supposed to occur for every set value, only one PEEP level was formally tested. Theoretical predictions were not confirmed at 6 ATA because such a depth is not possible with our chamber. Also, gas mixtures other than air, such as heliox, were not 
Table 1 Evaluation in volume control of the delivered tidal volume at various atmospheric pressures (ATA level)

\begin{tabular}{|c|c|c|c|c|c|}
\hline \multirow[t]{2}{*}{ ATA } & \multirow[t]{2}{*}{ Set $V_{\mathrm{T}}(\mathrm{ml})$} & \multirow{2}{*}{$\begin{array}{l}V_{\mathrm{T}} \text { predicted by } \\
\text { gas laws }(\mathrm{ml})\end{array}$} & \multicolumn{3}{|c|}{ Inspiratory:expiratory ratio } \\
\hline & & & $\begin{array}{l}1: 2 \\
V_{\mathrm{T}}(\mathrm{ml})\end{array}$ & $\begin{array}{l}1: 3 \\
V_{\mathrm{T}}(\mathrm{ml})\end{array}$ & $\begin{array}{l}1: 4 \\
V_{\mathrm{T}}(\mathrm{ml})\end{array}$ \\
\hline & & & $V_{\operatorname{Tmax}} 2,200$ & $V_{\operatorname{Tmax}} 1,650$ & $V_{\mathrm{Tmax}} 1,320$ \\
\hline \multirow[t]{4}{*}{1} & $\begin{array}{l}250 \\
500\end{array}$ & $\begin{array}{l}250 \\
500\end{array}$ & $\begin{array}{l}245 \\
485\end{array}$ & $\begin{array}{l}245 \\
485\end{array}$ & $\begin{array}{l}240 \\
485\end{array}$ \\
\hline & 750 & 750 & 740 & 760 & 815 \\
\hline & 1,000 & 1,000 & 1,070 & 1,110 & 1,120 \\
\hline & & & $V_{\text {Tmax }} 1,000$ & $V_{\operatorname{Tmax}} 750$ & $V_{\text {Tmax }} 600$ \\
\hline \multirow[t]{5}{*}{2.2} & 250 & 168 & 300 & 290 & 280 \\
\hline & 500 & 335 & 545 & $\mathbf{5 5 0}$ & $\mathbf{5 5 0}$ \\
\hline & 750 & 502 & 830 & 830 & 655 \\
\hline & 1,000 & 670 & 1,065 & 815 & 645 \\
\hline & & & $V_{\operatorname{Tmax}} 785$ & $V_{\operatorname{Tmax}} 590$ & $V_{\text {Tmax }} 475$ \\
\hline \multirow[t]{5}{*}{2.8} & 250 & 150 & 235 & 240 & 245 \\
\hline & 500 & 300 & 495 & 520 & 470 \\
\hline & 750 & 450 & 770 & 590 & 475 \\
\hline & 1,000 & 600 & 775 & 590 & 495 \\
\hline & & & $V_{\operatorname{Tmax}} 550$ & $V_{\text {Tmax }} 415$ & $V_{\text {Tmax }} 330$ \\
\hline \multirow{4}{*}{4} & 250 & 125 & 205 & 210 & 220 \\
\hline & 500 & 250 & 445 & 420 & 325 \\
\hline & 750 & 375 & 535 & 405 & 330 \\
\hline & 1,000 & 500 & 550 & 405 & 330 \\
\hline
\end{tabular}

Measured $V_{\mathrm{T}} \mathrm{s}$ are depicted and compared to set $V_{\mathrm{T}}$. Data in black observed between the measured $V_{\mathrm{T}}$ and predicted $V_{\mathrm{Tmax}}$, confirming indicate the proper compensation with settings inside the compensation range of the ventilator (set $V_{\mathrm{T}}$ under $V_{\mathrm{Tmax}}$ ). With settings outside the range, the $V_{\mathrm{T}}$ decreased with increasing ATA level (italic values). When the range was exceeded, close agreement was our calculations

$A T A$ absolute atmosphere, $V_{T}$ tidal volume, $V_{T \max }$ predicted maximal $V_{\mathrm{T}}$ for a given setting and ATA level

Table 2 Practical user's guide for the IPER 1000 in volume-control mode

\begin{tabular}{|c|c|c|c|c|c|c|c|c|c|c|c|c|}
\hline \multirow[t]{3}{*}{ I:E ratio } & \multicolumn{12}{|c|}{ Predicted $V_{\text {Tmax }}(\mathrm{mL})$} \\
\hline & \multicolumn{3}{|c|}{2.2 ATA } & \multicolumn{3}{|c|}{2.8 ATA } & \multicolumn{3}{|c|}{4 ATA } & \multicolumn{3}{|c|}{6 ATA } \\
\hline & $1: 2$ & $1: 3$ & $1: 4$ & $1: 2$ & $1: 3$ & $1: 4$ & $1: 2$ & $1: 3$ & $1: 4$ & $1: 2$ & $1: 3$ & $1: 4$ \\
\hline \multicolumn{13}{|l|}{ Rate } \\
\hline 10 & 1500 & 1125 & 900 & 1180 & 885 & 705 & 825 & 620 & 495 & 550 & 415 & 330 \\
\hline 15 & 1000 & 750 & 600 & 785 & 590 & 470 & 550 & 415 & 330 & 365 & 275 & 220 \\
\hline 20 & 750 & 565 & 450 & 590 & 440 & 355 & 415 & 310 & 250 & 275 & 205 & 165 \\
\hline$V_{\text {Emax }}\left(1 \min ^{-1}\right)$ & 15.0 & 11.3 & 9.0 & 11.8 & 8.9 & 7.1 & 8.3 & 6.2 & 5.0 & 5.5 & 4.2 & 3.3 \\
\hline
\end{tabular}

Based on theoretical predictions and experimental measurements, the predicted $V_{\mathrm{T}} \mathrm{max}$ is presented according to the ATA level and frequently used combinations of the respiratory rate and inspiratory:expiratory ratio. The predicted $V_{\text {Emax }}$ is also shown in bold

tested because their use is not approved with the IPER 1000 , but wide variations in $V_{\mathrm{T}}$ should be expected.

It can be appreciated that a hyperbaric environment poses a challenge for manufacturers; the alternatives to the IPER 1000 also have limitations. With monoplace chambers, the ventilator unit is kept outside of the chamber. The Sechrist 500A and the Omni-vent have been used in this context, but limited performances and capabilities (control mode only) were shown by Weaver et al. [11, 12]. For multiplace chambers, the ventilator must be placed in the enclosure, allowing manipulations by the caregivers. Most of the ventilators tested in one
ATA absolute atmosphere, $V_{T}$ max predicted maximal $V_{\mathrm{T}}$ in given conditions, $V_{E} \max$ predicted maximal minute ventilation

report have shown unacceptable performance, mainly because of insufficient $V_{\mathrm{E}}$ [5]. Some older devices, such as the Monaghan 225, have also been used in the past, but technical support is now difficult with these devices [13]. Modified standard ICU ventilators have been bench tested with variable results, but none are currently approved for use in clinical practice [4]. Despite not being approved for hyperbaric use, the Impact UNI-VENT Eagle 754 ventilator was shown to provide a stable $V_{\mathrm{E}}$ under various supra-atmospheric pressures [14]. The recently FDAapproved Atlantis ventilator also has generated a lot of interest, but also suffers from several drawbacks as it 
provides only control ventilation and is devoid of alarms, and the compensation mechanism is not in function when used in a multiplace chamber. Interestingly, a hyperbariccompatible version of the Servo-i (Maquet, Solna, Sweden) is expected on the market by mid- 2012 .

\section{Conclusion}

The Siaretron IPER 1000 ventilator attempts to maintain a constant $V_{\mathrm{T}}$ at various ambient pressures by adjusting the inspiratory valve opening. Clinicians should be aware of the range of compensation, which is predictable for each ATA level. Setting a $V_{\mathrm{T}}$ outside the range can result in an unwanted decrease in $V_{\mathrm{E}}$ with adverse clinical consequences. The maximal $V_{\mathrm{E}}$ provided by the ventilator may be insufficient, especially at high ATA levels and for patients with lung injuries and moderate-high ventilatory needs. The manufacturer should consider restricting the settings to those within the operational range of the ventilator.

\section{References}

1. Weaver LK (2011) Hyperbaric oxygen in the critically ill. Crit Care Med 39:1784-1791

2. Skinner M (1998) Ventilator function under hyperbaric conditions. Diving Hyperb Med J 28:62-71

3. Workman WT (1999) Hyperbaric facility safety: a practical guide. Best Pub. Co., Flagstaff

4. Stahl W, Radermacher P, Calzia E (2000) Functioning of ICU ventilators under hyperbaric conditionscomparison of volume- and pressurecontrolled modes. Intensive Care Med $26: 442-448$

5. Stanga D, Beck G, Chimiak J (2003) Evaluation of respiratory support devices for use in the hyperbaric chamber. NEDU TR 03-18 Panama City, FL, Department of Defense, Navy Experimental Diving Unit

6. Blanch PB, Desautels DA, Gallagher TJ (1989) Mechanical ventilator function under hyperbaric conditions. Undersea Hyperb Med 16 (Supp):17
7. Lyazidi A, Thille AW, Carteaux G, Galia F, Brochard L, Richard JC (2010) Bench test evaluation of volume delivered by modern ICU ventilators during volume-controlled ventilation. Intensive Care Med 36:2074-2080

8. Thille AW, Lyazidi A, Richard JC, Galia F, Brochard L (2009) A bench study of intensive-care-unit ventilators: new versus old and turbine-based versus compressed gas-based ventilators. Intensive Care Med 35:1368-1376

9. West JB (1999) The original presentation of Boyle's law. J Appl Physiol 87:1543-1545

10. Tassaux D, Jolliet P, Thouret JM, Roeseler J, Dorne R, Chevrolet JC (1999) Calibration of seven ICU ventilators for mechanical ventilation with helium-oxygen mixtures. Am J Respir Crit Care Med 160:22-32

11. Weaver LK, Greenway L, Elliot CG (1988) Performance of the Sechrist 500A hyperbaric ventilator in a monoplace hyperbaric chamber. J Hyperb Med 3:215-225
12. Churchill S, Weaver LK, Haberstock D (1999) Performance of the Omni-vent mechanical ventilator for use with the monoplace hyperbaric chamber. Undersea Hyperb Med 26(Suppl):70-71

13. Moon RE, Bergquist LV, Conklin B, Miller JN (1986) Monaghan 225 ventilator use under hyperbaric conditions. Chest 89:846-851

14. Hennessey PJ (2007) Evaluation of the UNI-VENT Eagle Model 754 ventilator for use in the surface recompression chambers (SRC) of the submarine rescue diving and recompression system (SRDRS). NEDU TR 07-03 Panama City, FL, Department of Defense, Navy Experimental Diving Unit 